\title{
¿Upper-Slope Jets and Gulf Stream Filaments Inshore of the Charleston Bump during Winter 2012
}

\author{
HARVEY SEIM \\ University of North Carolina at Chapel Hill, Chapel Hill, North Carolina \\ CATHERINE EDWARDS \\ Skidaway Institute of Oceanography, University of Georgia, Savannah, Georgia
}

(Manuscript received 4 October 2018, in final form 17 March 2019)

\begin{abstract}
A 3-month-long field program conducted in winter 2012 inshore of the seaward deflection of the Gulf Stream at the Charleston Bump observed several 7-21-day periods of strong $\left(>0.5 \mathrm{~m} \mathrm{~s}^{-1}\right)$ equatorward alongshelf flow over the upper continental slope. In sea surface temperature images, these phenomena resemble and appear linked to warm filaments, features known to be associated with meanders of the Gulf Stream as it traverses the southeast coast of North America. However, the character of these upper-slope features differs from previous descriptions of filaments, hence we describe them as "upper-slope jets." We document the characteristics of the jets, which are approximately $30 \mathrm{~km}$ in width, centered on the $200-\mathrm{m}$ isobath, with a maximum temperature variation at depth, and reasonably long-lived. Southwestward flow within the jet extends to $200 \mathrm{~m}$ and is in approximate thermal wind balance below a surface mixed layer. Maximum transport is estimated to be about $2.0 \mathrm{~Sv}\left(1 \mathrm{~Sv} \equiv 10^{6} \mathrm{~m}^{3} \mathrm{~s}^{-1}\right)$, driving a net equatorward along-shelf velocity over the deployment period. For this time period, at least, the jets form the equatorward flow of the shoreward flank of the Charleston Gyre. We suggest the features resemble the Pinocchio's Nose Intrusion recently described by Zhang and Gawarkiewicz. Large-amplitude meander crests with sufficiently strong curvature vorticity are a plausible source of initiation of the upper-slope jets.
\end{abstract}

\section{Introduction}

Shelfbreak and upper-slope jets (USJs) are relatively common features of the world's broader continental shelves, being well characterized along the Mid-Atlantic Bight (MAB; e.g., Gawarkiewicz and Chapman 1992), the northwest European shelf (e.g., Pingree et al. 1982), and in the Arctic along the Beaufort Sea (Nikolopoulos et al. 2009; von Appen and Pickart 2012). Density contrasts between the shelf and slope waters force these flows, with topographic steering causing flow to align parallel to isobaths and lighter shelf waters typically producing flow in the direction of topographic wave propagation.

We document an intermittent slope current that appears to be a special case of USJ, because it is found inshore of a western boundary current (the Gulf Stream)

D Denotes content that is immediately available upon publication as open access.

Corresponding author: Harvey Seim, hseim@email.unc.edu and at a time when the shelf waters are denser than those over the slope. The USJ flow was quite energetic, with speeds of $0.8 \mathrm{~m} \mathrm{~s}^{-1}$, and carried more than a Sverdrup (Sv; $1 \mathrm{~Sv} \equiv 10^{6} \mathrm{~m}^{3} \mathrm{~s}^{-1}$ ) of transport. As such, these USJs may be important to cross-shelf exchange and mass distribution over the slope.

The observed features and their elongation over time resemble those recently described in the MAB as Pinocchio's Nose Intrusions (PNIs) by Zhang and Gawarkiewicz (2015). However, if the generation mechanism for these jets in the South Atlantic Bight (SAB) is similar to that described for PNIs, the presence of the Gulf Stream would place constraints on the source waters, with interesting implications for the nature of the interaction of the Gulf Stream with the upper slope.

We first provide some background on the Gulf Stream and its inshore features along the SAB; most importantly, we review descriptions of warm filaments, which have a surface signature similar to the USJs we observed in the SAB. After briefly describing the field program, we document the character of the USJs and distinguish 


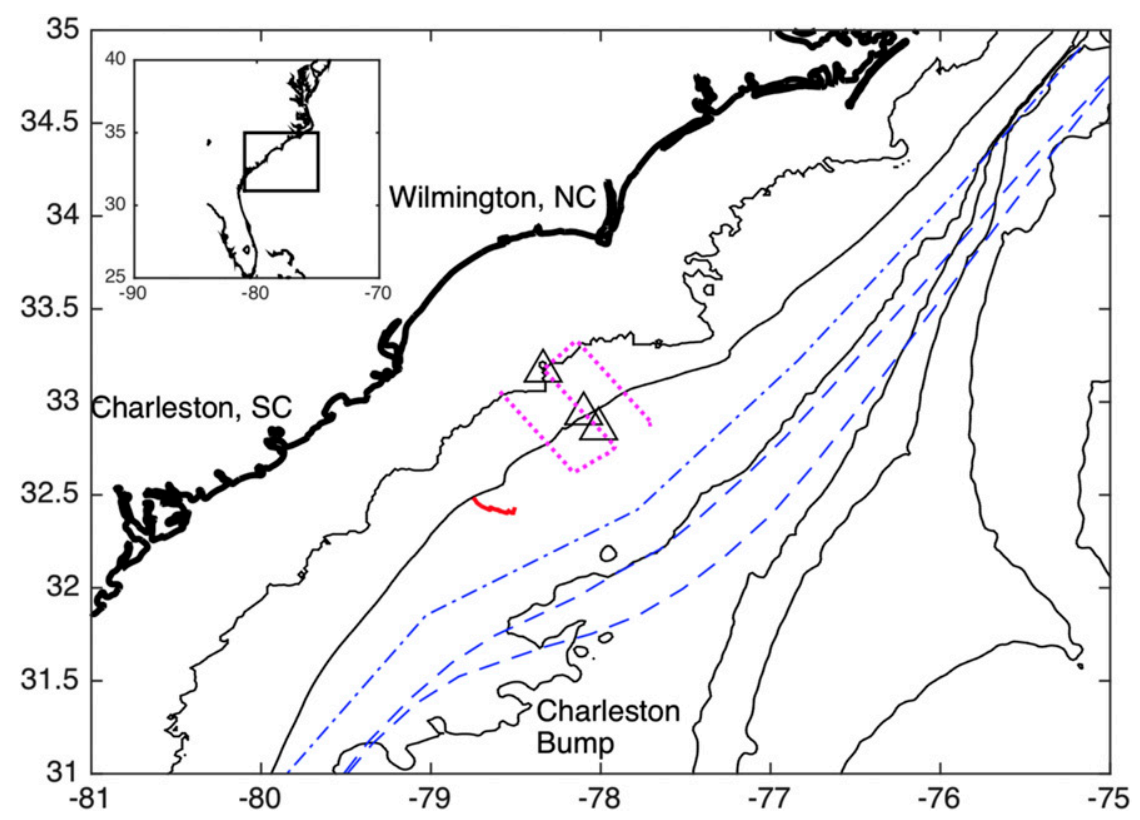

FIG. 1. Map of study area. Triangles mark mooring locations. Ship track of observations in Fig. 5 is dotted magenta. The red line marks the glider trajectory in Fig. 7. Dashed blue lines are average weakly and strongly deflected Gulf Stream paths of the maximum current from Zeng and $\mathrm{He}$ (2016); the dash-dot line marks average shoreward Gulf Stream thermal front location from Miller (1994). Black lines are isobaths at 30, 100, 600, 1000, 2000, 3000, and $4000 \mathrm{~m}$.

them from the better-known warm filaments using observations of the most energetic jets we observed. We then describe the variation in circulation over the upper slope over the duration of the 3-month field program. Implications of the USJs are discussed and a possible dynamical explanation for the USJs is then offered and explored.

\section{Background}

The Gulf Stream path, as indicated by its shoreward surface temperature front (e.g., Miller 1994) or a specific elevation in absolute sea surface height (Gula et al. 2015; Zeng and He 2016), follows the upper continental slope along the SAB, except for a seaward deflection near $32^{\circ} \mathrm{N}$ associated with a slope topographic feature known as the Charleston Bump. Bane and Dewar (1988) described the Gulf Stream path along the SAB as bimodal, in either a weakly or strongly deflected state at the Charleston Bump, behavior recently confirmed in a modeling study (Gula et al. 2015) and in an analysis of altimetry data (Zeng and $\mathrm{He} 2016$ ). The Zeng and $\mathrm{He}$ (2016) estimate of jet position (inferred from contour of elevation corresponding to maximum slope, indicated in Fig. 1) in the weakly deflected state lies approximately $30-40 \mathrm{~km}$ offshore of the Miller thermal front position. The strongly deflected state is shifted roughly $30 \mathrm{~km}$ (Fig. 1) in the mean, with a weak wintertime preference for the strongly deflected state. The study does not quantify variability about this average shift.

The Gulf Stream is also prone to instabilities, characterized by meanders in its path that have along-stream scales of $100-300 \mathrm{~km}$ in the SAB (Lee et al. 1991; Bane and Dewar 1988). Extensive studies of the dynamics, conducted during the 1980s (see Lee et al. 1991), led to a description of the instabilities, including the frontal eddies that develop in the meander troughs (seaward excursions relative to the mean path) and the warm filaments that extend off the meander crests (landward excursions relative to the mean path). Figure $2 \mathrm{a}$ is a schematic reproduced from Lee et al. (1991), based on observations collected upstream of the Charleston Bump, that shows how the cyclonic circulation around frontal eddies flood the upper slope and outer shelf with cooler, nutrient-rich water, overlain by a thin, warm buoyant plume of Gulf Stream water often called a warm filament. Studies by Bane et al. (1981), Bane and Dewar (1988), and Glenn and Ebbesmeyer (1994a,b) documented similar features and dynamics downstream of the Charleston Bump, where the meander amplitudes and frontal eddies tend to be larger, presumably because of the greater separation of the Gulf Stream from the shelf break. Bane and Dewar (1988) suggest that the bimodality of the deflection state is accompanied by changes in the properties of the meanders downstream 

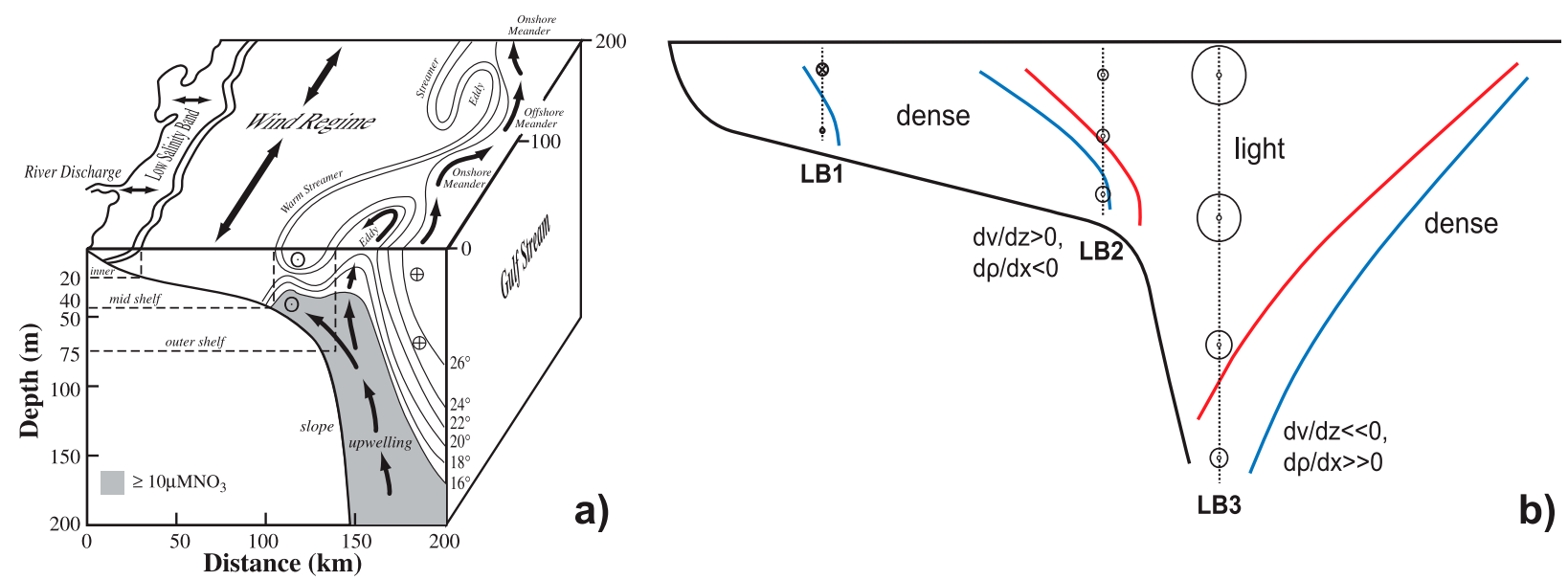

FIG. 2. (a) Schematic depiction of Gulf Stream meanders, frontal eddies, and warm filaments (labeled "warm streamer") as observed along the South Atlantic Bight, from Lee et al. (1991). Note the upwelling of cooler, nutrient-rich waters under the warm filaments. (b) Schematic depiction of upper-slope jet during winter, showing isotherms (red warmer than blue) and contrasting thermal wind regimes.

of the Charleston Bump, which have a longer period and greater size when the Gulf Stream is strongly deflected.

Warm filaments are shallow (of order $50 \mathrm{~m}$ ), surface trapped features made up of warm fluid entrained onto the outer shelf by the frontal eddies from a meander crest. Glenn and Ebbesmeyer (1994a,b) found equatorward flow of up to $0.5 \mathrm{~m} \mathrm{~s}^{-1}$ to occur in the warm filaments, as measured on the $75-\mathrm{m}$ isobath, but that the net flow averaged over a meander passage was nearly zero. Strongest equatorward flow occurred when large meanders were present. They also found that, based on surface drifter tracks, there was weak anticyclonic flow in the warm filaments, and that the filaments were more likely to penetrate onto the shelf when meander scales were large.

An early classification of Gulf Stream path variations in the region by Legeckis (1979) noted another mode of variability (type 3 in Fig. 7 of his paper) in which a warm filament becomes extensively elongated, specifically in the region inshore of the Gulf Stream deflection at the Charleston Bump. An example of such a feature from the time of our field program is shown in Fig. 3. In this case, warm waters inshore of the main body of the Gulf Stream extend alongshore over several hundred kilometers, apparently linked to several meanders of the Stream. Just downstream of the Charleston Bump, the Gulf Stream appears to be in a strongly deflected state, with an approximately $25-\mathrm{km}$ deflection from the multiyear mean position of the shoreward edge of the Gulf Stream from Miller (1994). Here, we identify the inshore surface feature as a USJ, and speculate that the elongated filament mode of Legeckis (1979) describes the same phenomenon, which is dynamically distinct from a warm filament described above.

The region immediately inshore of the Gulf Stream deflection at the Charleston Bump is suspected to be an area of persistent (or at least recurring) cyclonic circulation, which has been called the Charleston Gyre (e.g., Bane et al. 2001). The USJs we observed were found over the upper slope in this same area and may represent the equatorward-flowing shoreward limb of the cyclonic circulation around the cold dome at the center of the Charleston Gyre positioned shoreward of the deflected Gulf Stream. We show below that our upper-slope current measurements are consistent with average equatorward flow required to close the circulation of any "gyre" in the mean state; however, it is the USJs that produce this average, and without them the along-slope flow would be nearly zero.

Zhang and Gawarkiewicz (2015) describe an intrusion of warm core ring water onto the MAB shelf and subsequent along-shelf propagation as a distinct jetlike feature over more than $200 \mathrm{~km}$. They suggest that vorticity dynamics explain the feature, rather than simple entrainment into the MAB shelfbreak jet. In particular, they show through modeling that onshore flow of fluid with anticyclonic relative vorticity leads to vortex squashing and resulting equatorward flow. The fluid thus self-advects, propagating alongshore. Consistent with earlier modeling studies of westwardpropagating eddies impinging on a boundary (Shi and Nof 1994), the 2015 modeling study found that equatorward jets form only when anticyclonic eddies encounter the boundary. So while the jets observed in the $\mathrm{SAB}$ are similar to the structures described by Zhang and Gawarkiewicz (2015), it is not obvious that the flow associated with frontal eddies, strong cyclonic features, is consistent with those dynamics. The PNI initiation mechanism suggests that some condition must be met that brings fluid with anticyclonic vorticity in the 


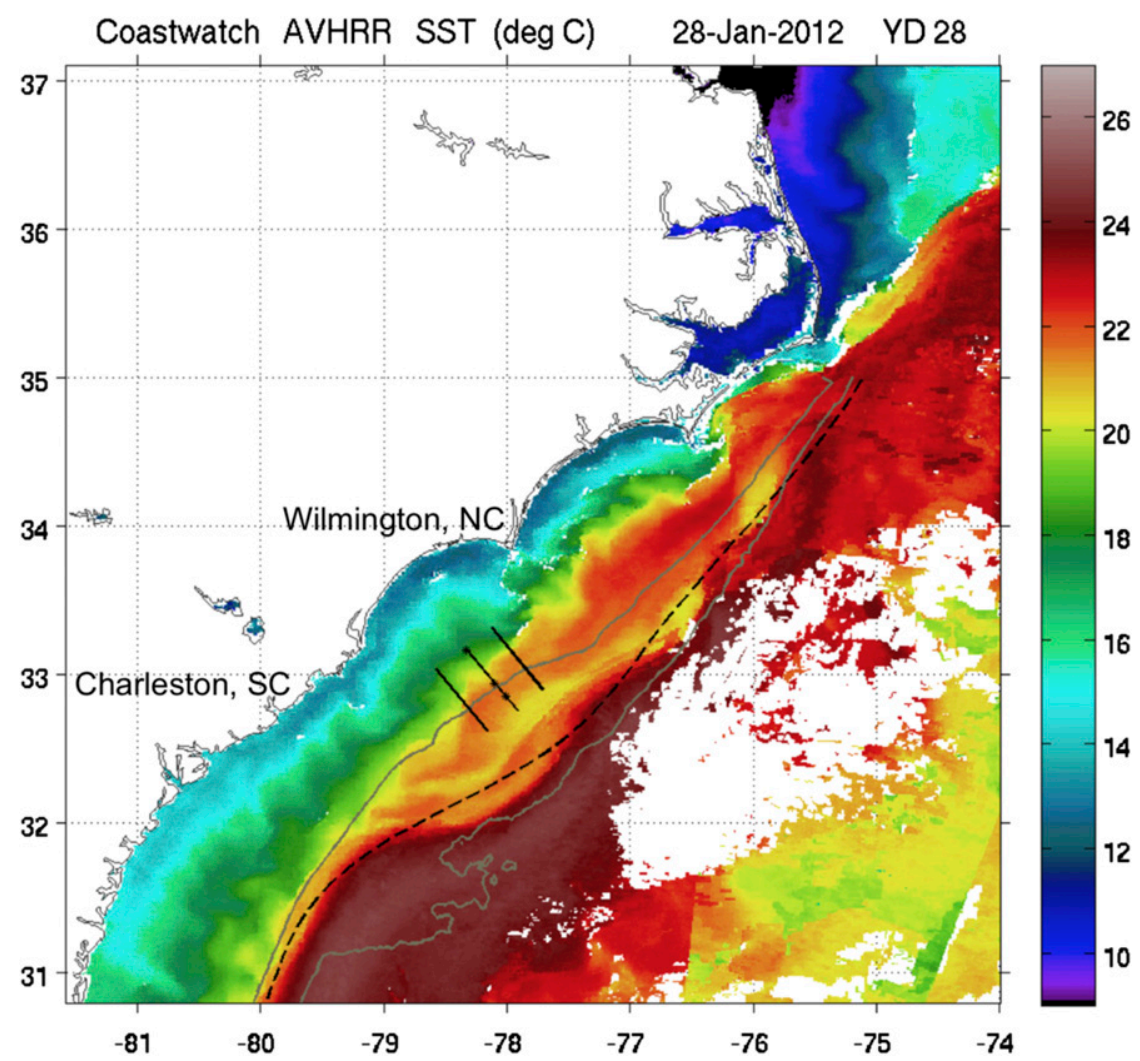

FIG. 3. SST image on 28 Jan 2012 derived from Coastwatch showing elongated warm feature being called an upper-slope jet. Light gray lines mark the 100- and 600-m isobaths. The dashed line is the mean position of the Gulf Stream shoreward temperature front from Miller (1994), black cross-shelf lines mark ship transect locations, and black stars mark mooring locations.

Gulf Stream in contact with the upper slope to initiate the jets.

\section{Methods}

Observations used in this paper come from a midJanuary to mid-April 2012 field program in Long Bay off the coast of South Carolina studying mechanisms supporting wintertime phytoplankton blooms. The program had three main observational components (Fig. 1). A cross-shelf line of three moorings, on the 30-, 75-, and 180-m isobaths, designated LB1, LB2, and LB3, respectively, measured full-depth velocity profiles with acoustic Doppler current profilers (ADCPs) and bottom temperature, salinity, and pressure with conductivitytemperature-depth (CTD; SBE 37) sensors. Three multiweek shipboard cruises aboard the R/V Savannah measured ADCP $(300 \mathrm{kHz})$ and CTD profiles (SBE 911), collected water samples for nutrients and characterization of the primary producers, and conducted towed body surveys using a SeaScience Acrobat with a SBE 19plus to depths of $65-70 \mathrm{~m}$ in a radiator pattern covering the study area. Two Slocum shallow-water gliders were also operated, one on the shelf, the other over the upper slope. We focus here on observations of currents, temperature, salinity, and density, collected with the mooring array, ship, and gliders.

Overall data quality was good. Quality control procedures removed spurious outliers in CTD records and ADCP data contaminated by either the surface (moored instruments) or bottom (shipboard instrument). Both gliders were outfitted with an unpumped SBE 41cp; a thermal lag correction developed by Garau et al. (2011) was implemented and significantly reduced salinity spiking [noticeable as reduced scatter in temperature/salinity $(T / s)$ plots]. Error and time constant offset and speeddependent slope parameters that performed best were found to be $\alpha_{0}=0.1587$ (nondimensional), $\alpha_{s}=0.0214$ (nondimensional), $\tau_{0}=6.5316(\mathrm{~s}), \tau_{s}=1.5969(\mathrm{~s})$ [see Eqs. (5) and (6) of Garau et al. (2011)], with a lag of approximately $7 \mathrm{~s}$.

Shipboard ADCP data were postprocessed to 5-min averages and corrected using shipboard GPS, as bottomtracking was not consistently available. Coverage of the 

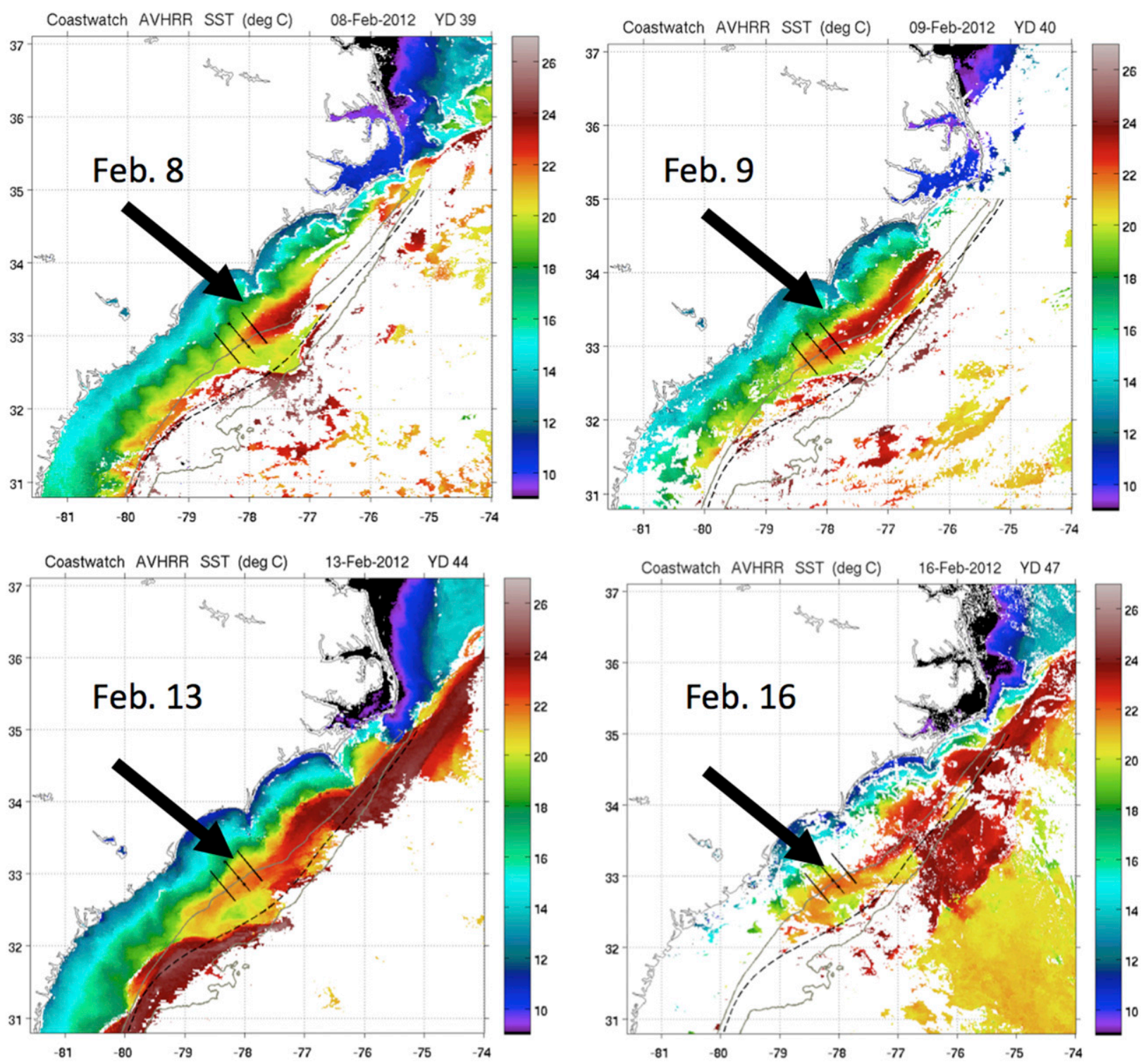

FIG. 4. SST sequence in mid-February 2012; other markings as in Fig. 3. In each panel the arrow points to the USJ.

shipboard ADCP dataset is limited to the upper $60 \mathrm{~m}$ of the water column. Shipboard ADCP records were detided by removing the barotropic tidal prediction for the largest 13 constituents of an ADCIRC tidal model with demonstrated model skill in representing current variability on the shelf off Georgia and South Carolina (Blanton et al. 2004).

\section{Results}

\section{a. $3 D$ structure of the USJ}

A sequence of SST images from mid-February 2012 illustrates the surface signature of a warm thermal feature progressing equatorward over the upper slope (Fig. 4). The tongue of warm water enters the sampling domain on 8 February, has clearly moved equatorward by 9 February, and extends to nearly $32^{\circ} \mathrm{N}$, where the Gulf Stream turns sharply offshore, by 13 February (the next clear image). The surface warm water persists as an along-shelf feature in the image from 16 February; clouds obscure the ocean surface for the next 10 days.

We identify the warm thermal feature on the slope as a USJ, and next use shipboard survey data from 14 February to describe its vertical structure. Figure 5 shows perspective views of shipboard surveys of the detided along-shelf currents (top) and temperature 

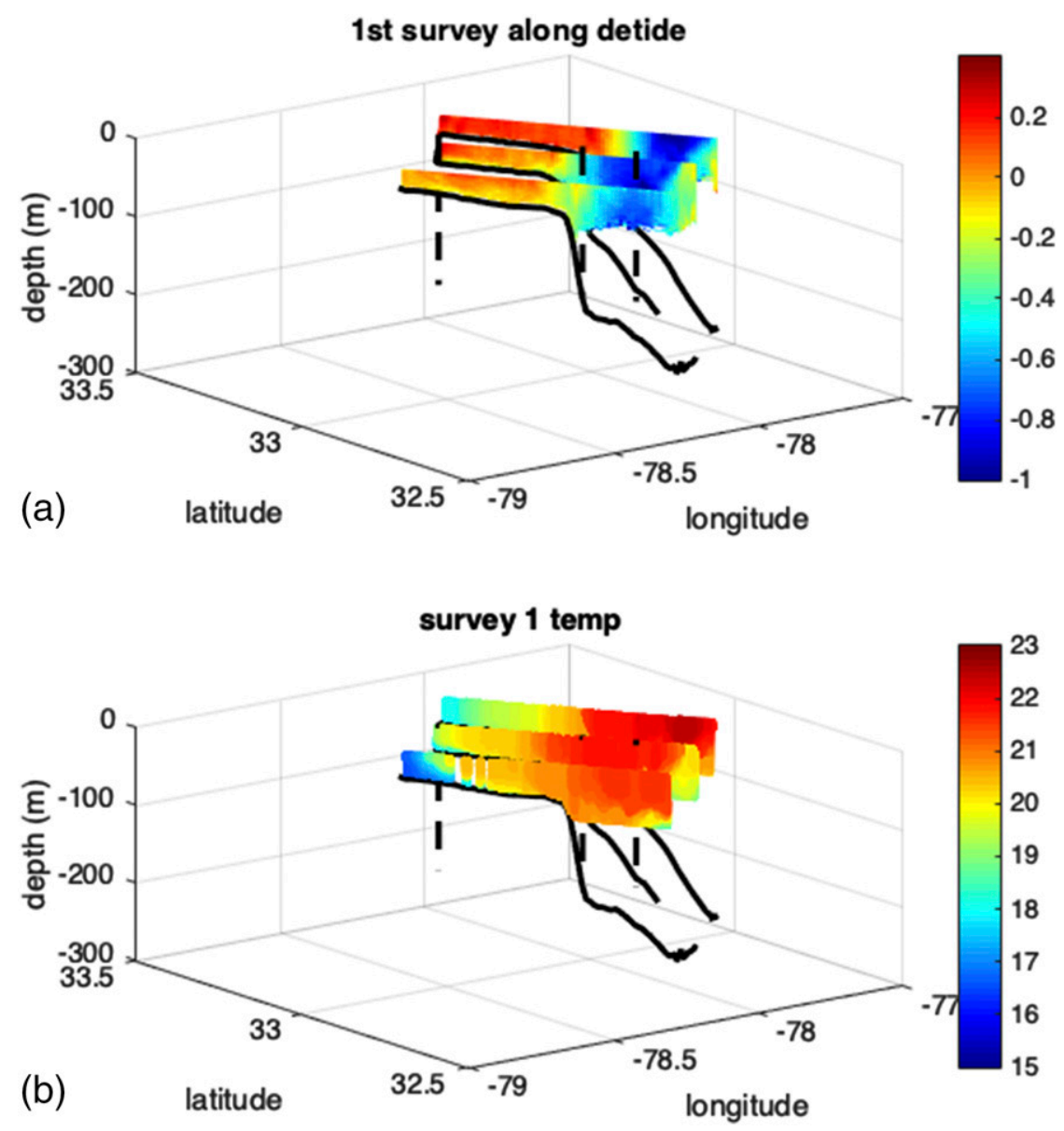

FIG. 5. Shipboard sampling sections from 14 Feb 2012: (a) detided along-shelf currents and (b) temperature field. Negative currents are oriented equatorward. Vertical dashed lines mark mooring locations.

field (bottom) over the upper $75 \mathrm{~m}$ (from shipboard ADCP and towed-body surveys, respectively). The USJ is clearly seen as a coherent feature in each of the crossshelf velocity transects (separated by $25 \mathrm{~km}$ along-shelf), flowing equatorward at up to $0.8 \mathrm{~m} \mathrm{~s}^{-1}$. The jet does not extend shoreward of the shelf break to any great extent in the velocity field. The core of the jet coincides with a local maximum in water temperature that does not extend far onto the shelf. A repeat survey conducted 4 days later (not shown) found similar conditions, except that the offshore position of the jet varied $5-8 \mathrm{~km}$ between transects.

The shipboard observations are sufficient to define several standard characteristics of the jet. Depth-averaging the velocity data from survey 1 and plotting as a function of cross-shelf distance illustrates that the velocity jet is about $30 \mathrm{~km}$ wide, more strongly sheared on its offshore side, and has a maximum velocity of $0.8 \mathrm{~m} \mathrm{~s}^{-1}$ averaged over the upper $75 \mathrm{~m}$ (Fig. 6). It is also clear that the jet lies largely over the upper slope and not on the shelf, though the strongest thermal gradients lie somewhat closer to shore as it moves equatorward. Depth-averaged flow at the middle and southern transect is near-zero over much of the shelf, and the northernmost reflects a poleward flow of $\sim 0.10 \mathrm{~m} \mathrm{~s}^{-1}$ driven by the onset of an along-shelf wind event. The vertical lines on Fig. 6 mark the locations of the bottom moorings and demonstrate that mooring LB3 sampled the center of the jet and that mooring LB2 sampled the anticyclonic (shoreward) flank.

Vertical relative vorticity, formed using only the crossshelf shear of the along-shelf current, exceeds $1 \times 10^{-4} \mathrm{~s}^{-1}$ in the offshore side of the jet for the two more southerly sections (Fig. 6c), with maximum values of half this magnitude in the onshore side. This asymmetry is apparent in Fig. 6 for these sections but not so for the northern section after the onset of wind-driven poleward shelf flow. Given the latitude of the feature 

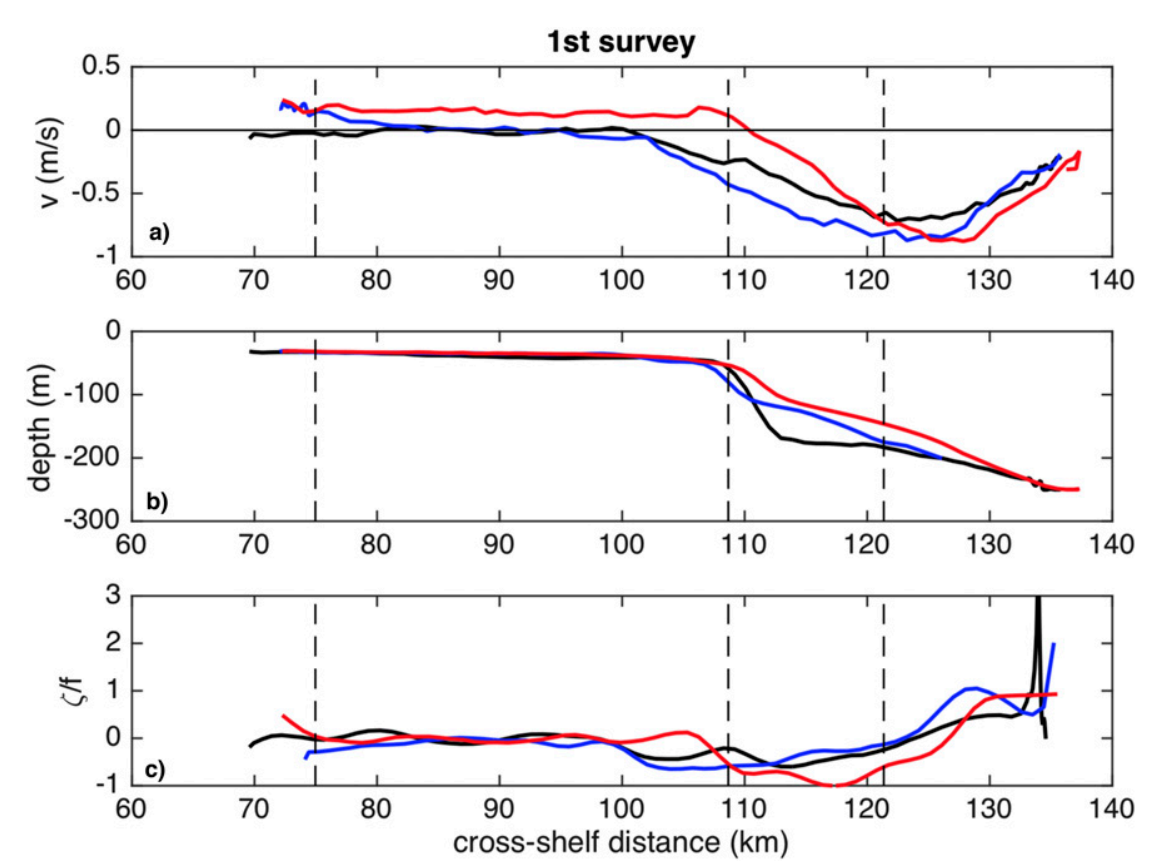

FIG. 6. (a) Depth-averaged along-shelf currents (detided), (b) bathymetry, and (c) relative vertical vorticity, scaled by the local Coriolis parameter, as a function of cross-shelf position. Black marks the southernmost section and red the northernmost. Dashed vertical lines mark the position of moorings.

$\left(f=7.8 \times 10^{-5} \mathrm{~s}^{-1}\right.$ at $\left.32.5^{\circ} \mathrm{N}\right)$, the Rossby number of the jet is $O(1)$ on its seaward side.

Figure 7 shows the temperature field down to $200 \mathrm{~m}$ in a cross-shelf section of the jet collected with a glider as it moves from the center of the cold dome associated with the Charleston Gyre toward the shelf (the track is shown on Fig. 1). Nearly all isotherms slope strongly downward toward the upper slope; for example, the $14^{\circ} \mathrm{C}$ isotherm is roughly $80 \mathrm{~m}$ deeper over the upper slope than in the center of the cold dome. The spatial structure of the observed isotherms is in contrast to the response to frontal eddy upwelling, for which isotherms uplift moving shoreward (Fig. 2). It is also worth noting that the density structure of the USJ feature is similar to that of a warm filament near surface, but with a larger vertical scale ( $>100 \mathrm{~m}$ as opposed to tens of meters).

The observed horizontal and vertical jet structure has a strong thermal signature; salinity variability is relatively weak and structure is largely driven by the Gulf Stream. Figure 8 presents a temperature/salinity $(T / s)$ histogram from all the glider and towed body observations, and is overlain with a $T / s$ envelope for the Florida Current from Schmitz et al. (1993). There is no obvious signature of shelf influence on the $T / s$ distribution, and in particular, no freshwater end member that could be used to infer shelf origins for water masses. The distribution indicates Florida Current/Gulf Stream waters occupy the study area from midshelf to the upper slope.

The vertical extent of the jet is made clear in time series observations from LB3, the mooring that is essentially in the middle of the jet (cf. Fig. 6). Beginning about 5 February, the along-shelf flow at all depths accelerates from near zero to around $0.5 \mathrm{~m} \mathrm{~s}^{-1}$ equatorward by 8 February (Fig. 9). At the same time the density field also adjusts, most strongly in the lower half of the water column, as less dense fluid floods the upper slope (Fig. 9b). Density surfaces below $100 \mathrm{~m}$ move downward more than $50 \mathrm{~m}$ in response. Bottom temperature at $\mathrm{LB} 3$ rises from $9^{\circ}$ to $16^{\circ} \mathrm{C}$, then fluctuates at the higher temperature as the jet speed varies (Fig. 9c). The along-shelf flow becomes more vertically sheared as the density field adjusts. This type of strong response in the lower half of the water column is inconsistent with a surface plume and is taken as evidence that the USJ is distinct from the frontal-eddy-associated warm filaments previously documented (e.g., Lee et al.1991; Bane et al. 1981).

Transport can be estimated directly in the upper water column, summing shipboard velocity where it is available across the jet; net transport from the surface to $60 \mathrm{~m}$ is $(1.0,1.0,1.4) \mathrm{Sv}$ for the three crossings (from south to north). This summation, however, fails to account for flow between 60-m depth and the seafloor. A numerical 


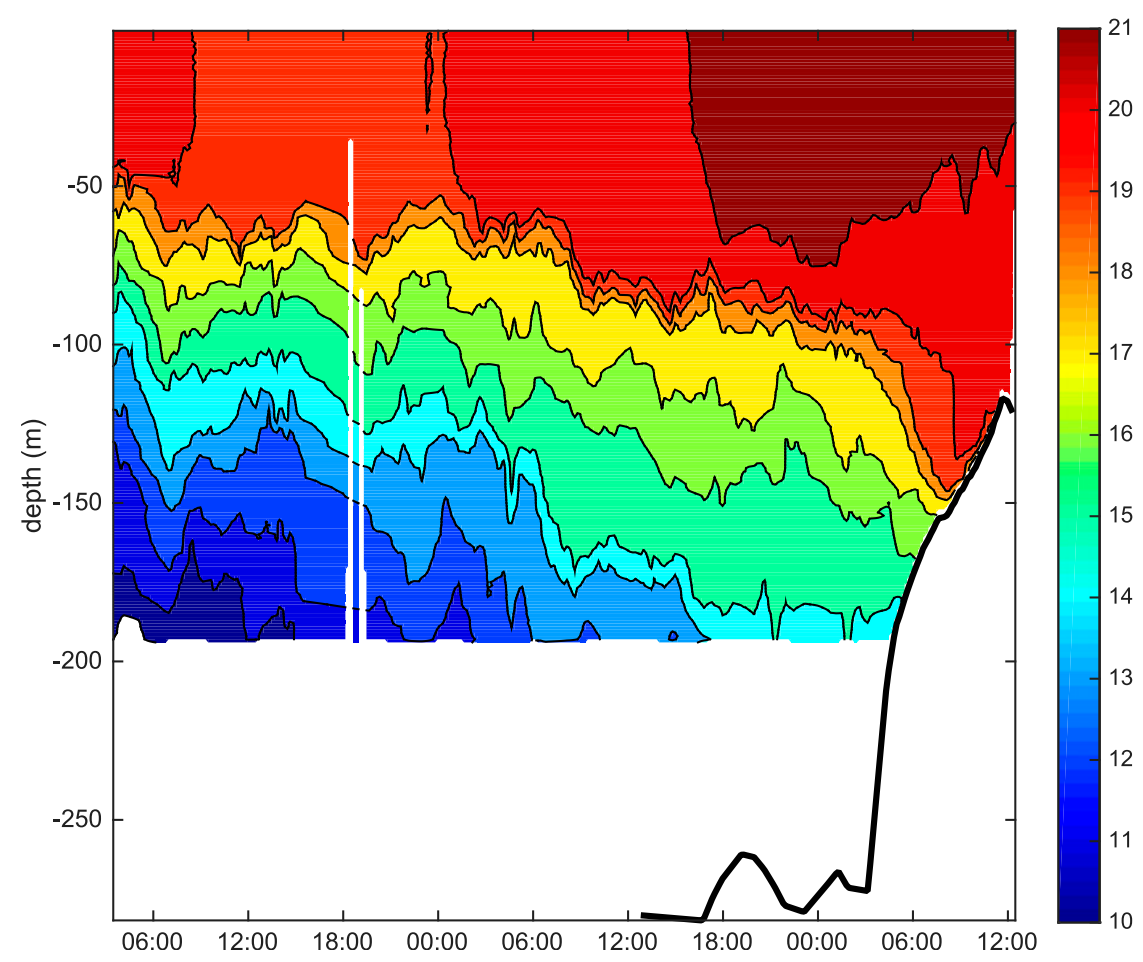

FIG. 7. Cross-slope temperature section collected with glider from near the center of the cold dome of the Charleston Gyre to the shelf break between 12 and 14 Feb; the thick black line shows the bottom depth where measured (the track is shown in Fig. 1).

summation of the measured depth-averaged current over the upper $60 \mathrm{~m}$ times the water depth between the 50 -and 200-m isobaths (half-width of the jet) yields (1.5, $1.8,1.4) \mathrm{Sv}$. This summation likely overestimates transport as Fig. 8 makes clear that the flow below $60 \mathrm{~m}$ is typically slower than above $60 \mathrm{~m}$. Assuming from Fig. 6 a half-width of $15 \mathrm{~km}$, a linear increase in depthaveraged speed from 0 to $0.8 \mathrm{~m} \mathrm{~s}^{-1}$ over this distance, and a linear depth change from 50 to $200 \mathrm{~m}$, the transport carried by the inshore half of the USJ is $0.9 \mathrm{~Sv}$. Assuming similar transport in the offshore half suggests a transport of $1.8 \mathrm{~Sv}$, as observed on 7 February in Fig. 9a. Taken together, these estimates suggest the USJ maximum transport is approximately $2 \mathrm{~Sv}$. This transport is large compared to that carried by the MAB shelfbreak front jet $(0.3 \mathrm{~Sv}$; Gawarkiewicz et al. 2008).

The velocity field develops vertical shear over the subsequent two days (8-9 February, cf. Fig. 9a), which may reduce the transport considerably. Depth-averaged currents measured at the LB2 and LB3 moorings decrease by $20 \%$ over this time period as a result of reduced flow at depth. To assess whether or not the vertical shear in the USJ is a result of establishing a thermal wind balance, we evaluate the terms of the thermal wind balance $\partial v / \partial z=-(g / f \rho) \partial \rho / \partial x$ using two pairs of simultaneous cross-shelf density gradient and along-shelf velocity measurements: 1) shipboard velocity data and towed body density measurements in the upper 60-65 m (Fig. 5), and 2) a combination of glider and moored data over the outer slope, taken with a number of assumptions outlined below. In all calculations, $v$ is the along-slope current, $z$ the vertical coordinate, $x$ the cross-slope direction, $f$ the Coriolis parameter, $g$ acceleration due to gravity, and $\rho$ the water density.

Using shipboard ADCP and towed body data, Fig. 10 displays the two terms in the balance and their difference as of function of cross-shelf position and depth for the middle section of Fig. 5 and is representative of the sections to the north and south. Despite the visual correspondence between regions of vertical shear and corresponding horizontal density gradients, especially on the offshore side of the USJ, the difference between the two fields indicates numerical correspondence in only limited regions. The rms values of the two fields are similar $\left(0.0060,0.0057 \mathrm{~s}^{-1}\right)$ but the rms of the difference field is not significantly different, indicating no predictive skill. The strong negative shear on the offshore side of the USJ is represented in the horizontal density gradients, but only a small portion of the broad region of positive vertical shear farther inshore can be explained by the density field. Possible explanations for the 


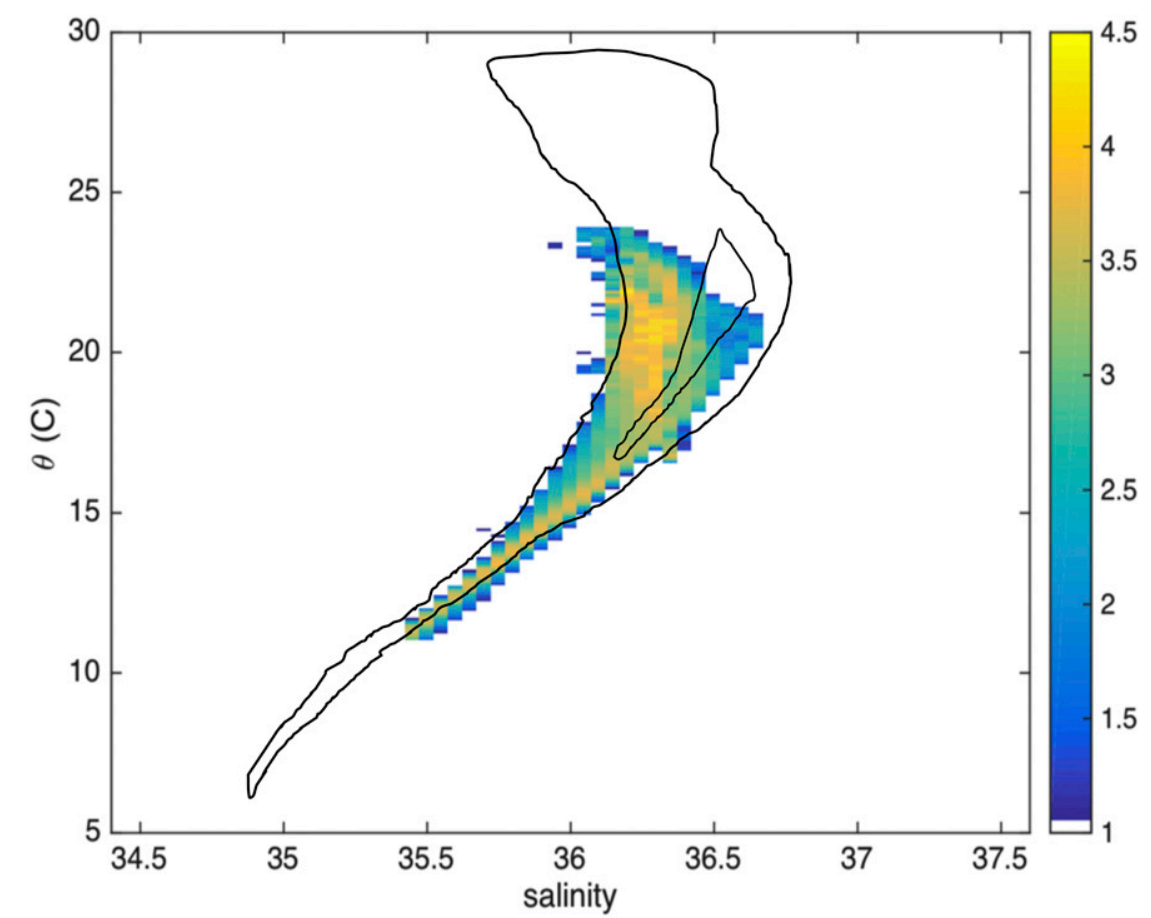

FIG. 8. Temperature/salinity histogram of all the observations collected with gliders and the towed body, calculated with bin sizes of $0.1^{\circ} \mathrm{C}$ and 0.05 , respectively. The number of observations is given in $\log$ base 10 for clarity, and the $T / s$ envelope for the Florida Current from Schmitz et al. (1993) is overlaid for reference. The observed distribution exhibits no significant departure from the Florida Current envelope, indicating Gulf Stream waters occupy the shelf and upper slope during the study period.

departure from a thermal wind balance are friction driven by wind stress at the surface, bottom stress and/ or tidal mixing on the inshore side of the USJ, and timedependent motions, like internal tides.

A second comparison of the two terms in the thermal wind relation can be derived from the glider section in Fig. 7 and the LB3 mooring, which is roughly $70 \mathrm{~km}$ upjet. Assuming some appropriate time offset and further, that the flow field does not change over that time/distance, the thermal wind balance can be evaluated over nearly the entire water column using the cross-slope density gradients measured with the glider and the vertical shear of the along-shelf current. Figure 11 compares the velocity and vertical shear profiles collected at LB3 averaged over 2 days starting on 14 February when the glider was near the 180-m isobath (while transiting onshore) with the estimated velocity profile and scaled horizontal density gradient from the glider, averaged over $6 \mathrm{~km}$ spanning the $180-\mathrm{m}$ isobath. The shears are similar below 60-m depth, though somewhat underestimated by the density field. Above $60 \mathrm{~m}$ the velocity shear is zero or positive, whereas the thermal wind shear remains negative, likely reflecting the poleward wind stress at the time. Evaluation of the thermal wind balance indicates only qualitative correlation within the upper $60 \mathrm{~m}$ and a better correspondence below this depth over the upper slope. These results (particularly at LB3) suggest a wind-mixed frictional surface layer atop a geostrophic interior.

\section{b. Upper-slope variability over 3 months}

We next examine variability over the upper slope and outer shelf over a 3-month period, from mid-January to mid-April of 2012, using 48-h low-passed along-shelf currents, collected with bottom mounted ADCPs on the 30-, 75-, and 180-m isobaths. The wind records are taken from NDBC buoys 41004 and 41013, located midshelf off Cape Romain and Cape Fear, the two capes that bound Long Bay to the south and north. There is little correlation between the records over the upper slope (LB3) and those at midshelf (LB1, the 30-m mooring); the lagged correlation coefficient is 0.27 at $7 \mathrm{~h}$ (LB1 leading LB3), which is significant at the $99 \%$ confidence level, but only $7 \%$ of the variance can be explained in a linear relationship (Figs. 12b,d). The midshelf alongshelf current at LB1 is largely wind-driven (linear correlation coefficient of 0.65 at 5-h lag between along-shelf wind stress and depth-averaged along-shelf current; 

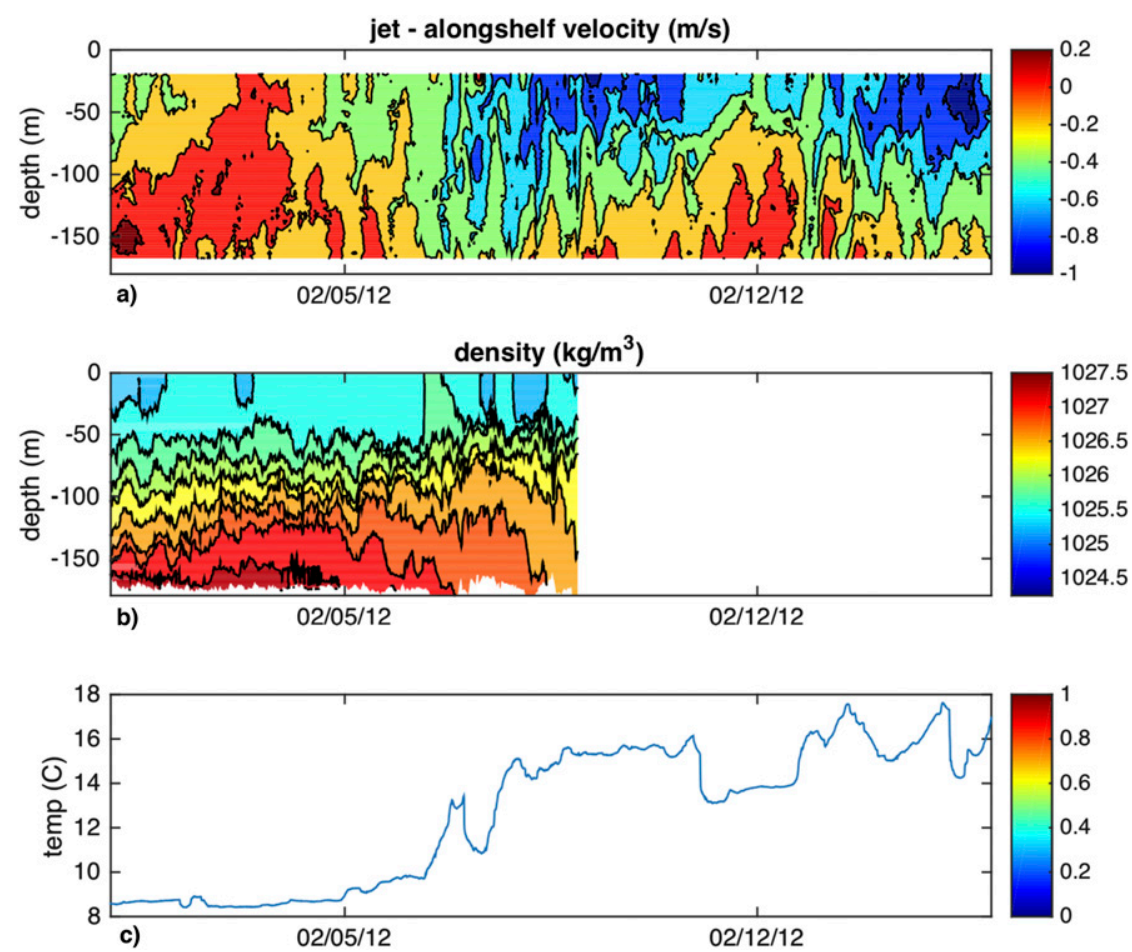

FIG. 9. (a) Along-shelf currents (from mooring) and (b) density (from glider) at or close to LB3 (currents were too strong for the glider to hold station after 8 Feb) and (c) bottom temperature at LB3.

Figs. 12a,b), whereas the upper-slope currents are not significantly correlated with the wind. The depth-averaged shelfbreak currents (LB2, Fig. 12c) are correlated with both the inshore (correlation coefficient of 0.58 at 10-h lag with LB1) and offshore (correlation coefficient of 0.55 at 4-h lag with LB3) currents. Strong equatorward flow, greatest at the surface and strongly sheared in the vertical but reaching to the seabed, dominates the upper-slope mooring from the beginning of the record until late February. Only one brief period of weak poleward flow occurs during this time, in early February. SST imagery confirms the presence of elongated filament-like structures during late January (Fig. 3) and throughout most of February (Fig. 4), consistent with an interpretation that the USJs persisted over this time period.

Around 24 February, the flow regime changes, with energetic, alternating poleward and equatorward flows on a weekly time scale after this time. The poleward flows in particular are surface-trapped to the upper $50 \mathrm{~m}$ or so (Fig. 12d). SST imagery indicates that the Gulf Stream is only weakly deflected by the Charleston Bump at this time, and we identify the pattern as that of typical meander passages over the mooring. During the last weeks of observations, the flow is less energetic, possibly reflecting meander passage when the Gulf
Stream is somewhat farther offshore but not strongly deflected, resulting in a weaker influence on the study site.

The USJs have a strong expression in bottom temperature. The mid-February event drives an $8^{\circ} \mathrm{C}$ increase in bottom temperatures on the upper slope (LB3), and similarly elevated temperatures occur in mid to late January and through much of February (Fig. 12e), consistent with the interpretation of the along-shelf velocity that the USJs persist over this time period. Bottom temperature at $75 \mathrm{~m}$ (LB2) is also elevated relative to the midshelf location during these times. Bottom temperatures at the shelf break and upper slope (LB2 and LB3) are elevated briefly in mid-March, suggesting the strong equatorward flow during that time period began to develop into a jet. Coolest bottom temperatures on the upper slope are associated with poleward nearbottom flow, in early February, late February, and late March.

The mean vertical profile of along-shelf velocities over the measurement period exhibit equatorward flow over the upper slope and shelf break and weakly poleward flow at midshelf (Fig. 13a). Zero or weakly positive vertical shear in shelf profiles and above $50 \mathrm{~m}$ in the upper-slope mean profile (Fig. 13a) appears to be a signature of thermal wind shear from the negative 

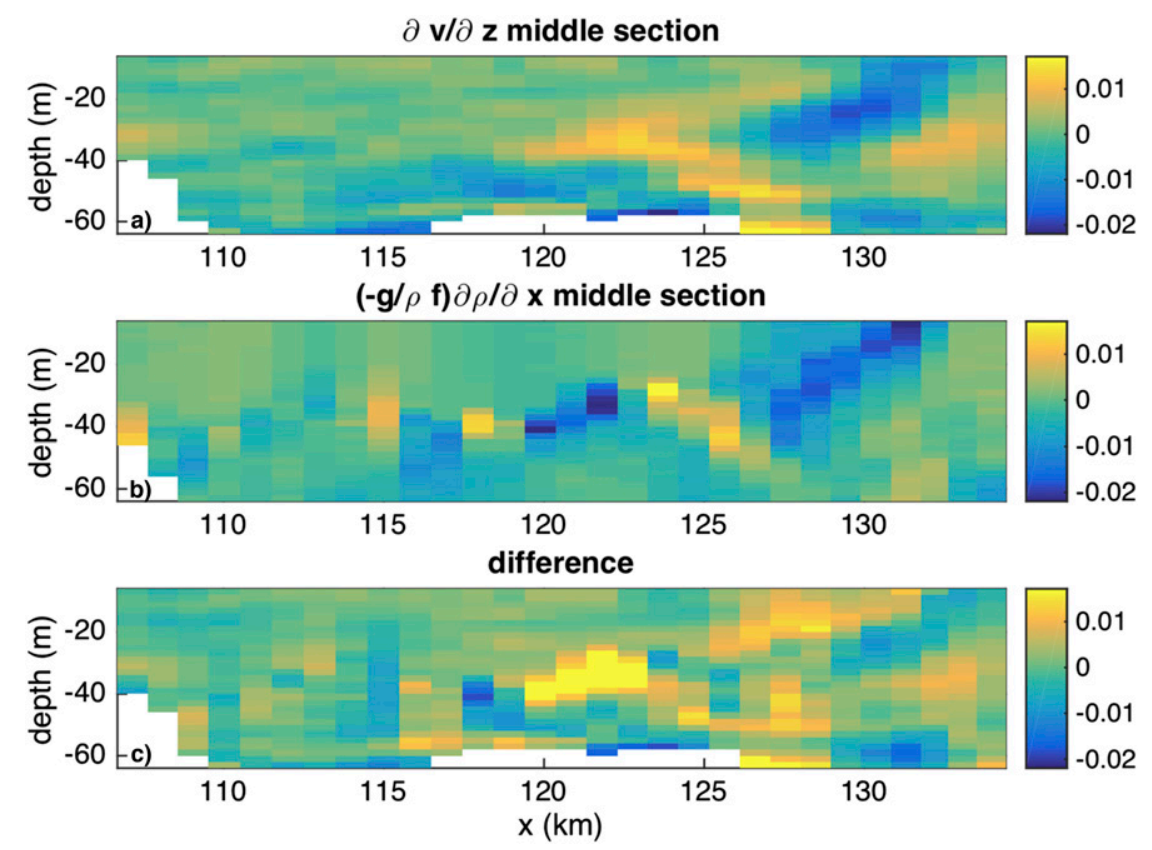

FIG. 10. Thermal wind balance evaluation $\left(\mathrm{s}^{-1}\right)$ along middle section of Fig. 5. (a) Vertical shear of along-slope current, (b) scaled cross-shelf horizontal density gradient, and (c) difference between top two panels.

offshore density gradient on the shelf in winter. Comparing glider measurements near the shelfbreak mooring with density measured with CTDs at LB1, we find a roughly $1 \mathrm{~kg} \mathrm{~m}^{-3}$ decrease in density averaged over the upper $30 \mathrm{~m}$ over a $33-\mathrm{km}$ separation distance. This change should produce a vertical shear of $0.0037 \mathrm{~s}^{-1}$, whereas the observed shear is $0.0015 \mathrm{~s}^{-1}$. The change in sign of the shear below $50 \mathrm{~m}$ over the upper slope
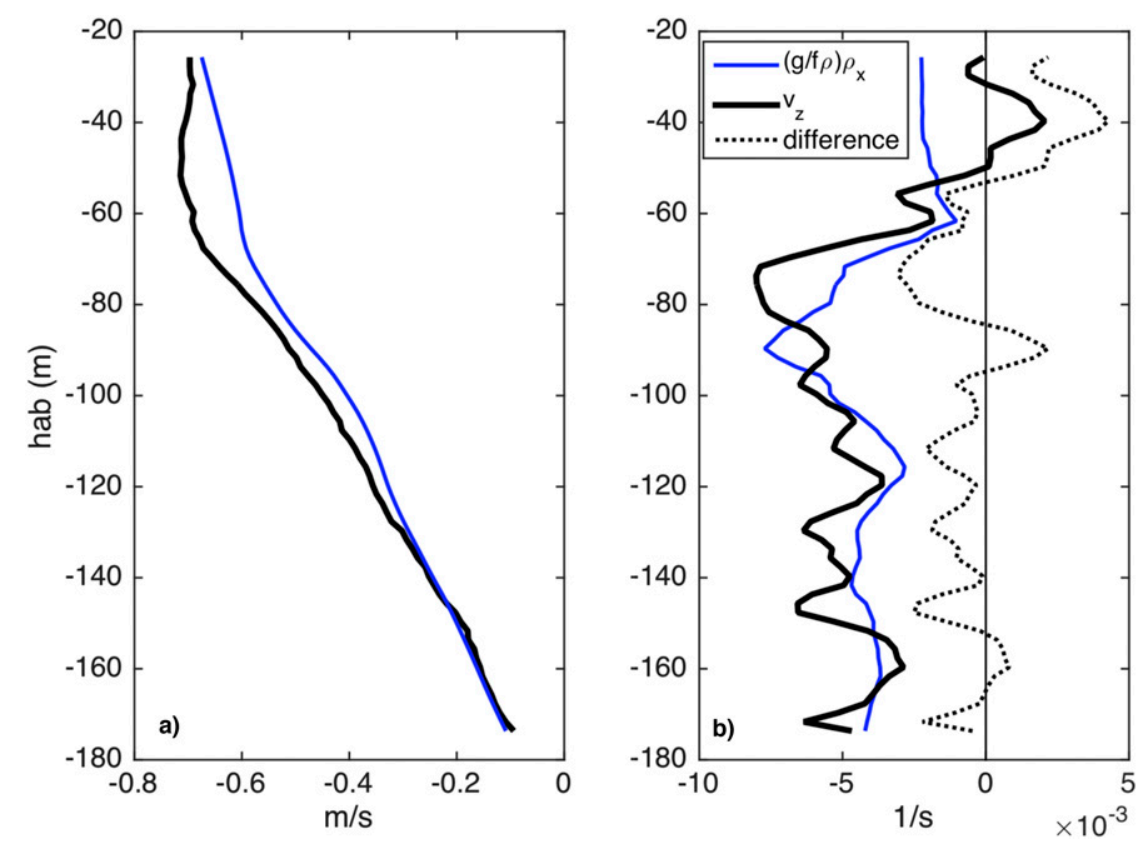

FIG. 11. Thermal wind balance evaluation on 180-m isobath along-glider section shown in Fig. 8. (a) The 2-day averaged current profile from LB3 (black) and integrated scaled density gradient (blue); (b) vertical shear (black), scaled density gradient (blue), and difference (dashed black). 


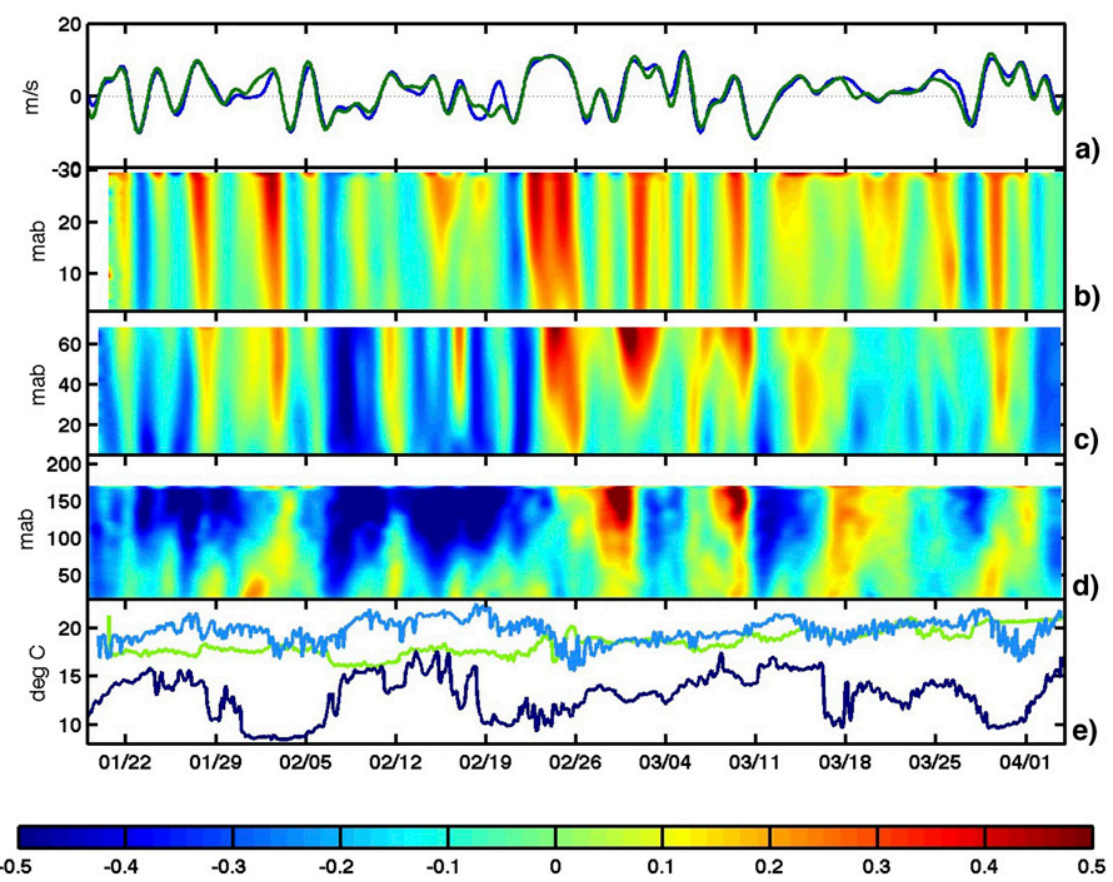

FIG. 12. (a) The 48-h low-passed along-shelf winds from NDBC buoys 41004 and 41013 (located off Cape Romain and Cape Fear, respectively), (b) 30-, (c) 75-, and (d) 180-m alongshelf currents, and (e) bottom temperatures at $30 \mathrm{~m}$ (green), $75 \mathrm{~m}$ (light blue), and $180 \mathrm{~m}$ (dark blue). Positive values of wind and currents are poleward.

mimics the change in the sign of the cross-shelf density gradient over the upper slope seen in Figs. 3, 5, and 7, and depicted schematically in Fig. 2.

Mean profiles of along-shelf flow formed using observations before and after late February are remarkably different (Fig. 13a), most notably over the upper slope, reflecting the dominant influence of the USJs on upper-slope flow compared to times when meanders are prevalent. Strong equatorward flow occurs when the jets are present, and near-zero mean flow occurs when meanders dominate the dynamics. Thus, at least for this measurement period, the nonzero record-long mean is due to the presence of the jets.

Mean cross-shelf velocities at LB3 are three-layered but weak $\left(<0.02 \mathrm{~m} \mathrm{~s}^{-1}\right)$, with onshore flow at middepth and offshore in the upper $40 \mathrm{~m}$ and the lower $20 \mathrm{~m}$ (Fig, 13b). Flow is slightly stronger $\left(0.03 \mathrm{~m} \mathrm{~s}^{-1}\right)$ and onshore during the USJs except in the lowest $20 \mathrm{~m}$, whereas when meander dynamics dominate, flow is offshore and somewhat stronger (up to $0.04 \mathrm{~m} \mathrm{~s}^{-1}$ ) over the upper $80 \mathrm{~m}$. Mean cross-shelf velocities are strongest at the shelf break. At midshelf, the crossshelf flows are weak, less than $0.01 \mathrm{~m} \mathrm{~s}^{-1}$. The enhanced offshore flow near the surface at LB2 and LB3 during meanders is likely wind-driven, as the average along-shelf wind stress during meanders $(+0.029 \mathrm{~Pa}$, poleward) is almost 3 times greater than during the USJs $(+0.010 \mathrm{~Pa})$.

\section{Discussion}

Due to the similarity in the sea surface temperature imagery signature of frontal-eddy-associated warm filaments and the features we are calling upper-slope jets, we point out here the characteristics of the USJs that distinguish them from warm filaments. Figure $2 b$ summarizes the temperature, density, and velocity structure of the USJs observed in this study; water properties and their gradients are in stark contrast to the canonical filament structure summarized in Fig. 2a. First, vertical shear in alongshore flow and the associated cross-shelf density gradients weaken in magnitude and change sign between LB2 and LB3. The reversal in sign implies a wedge-like shape to the jet consistent with shipboard observations. Second, despite having a similar position relative to the shelfbreak and cross-shelf scale similar to warm filaments, the USJs impact the density structure over the full depth of the water column, with the largest changes near the seafloor, unlike surface-trapped phenomena. Third, at depth, the response is strong warming, the opposite of that seen beneath warm filaments. Fourth, the velocity field responds over the full depth as well, rather than being a surface trapped feature. 

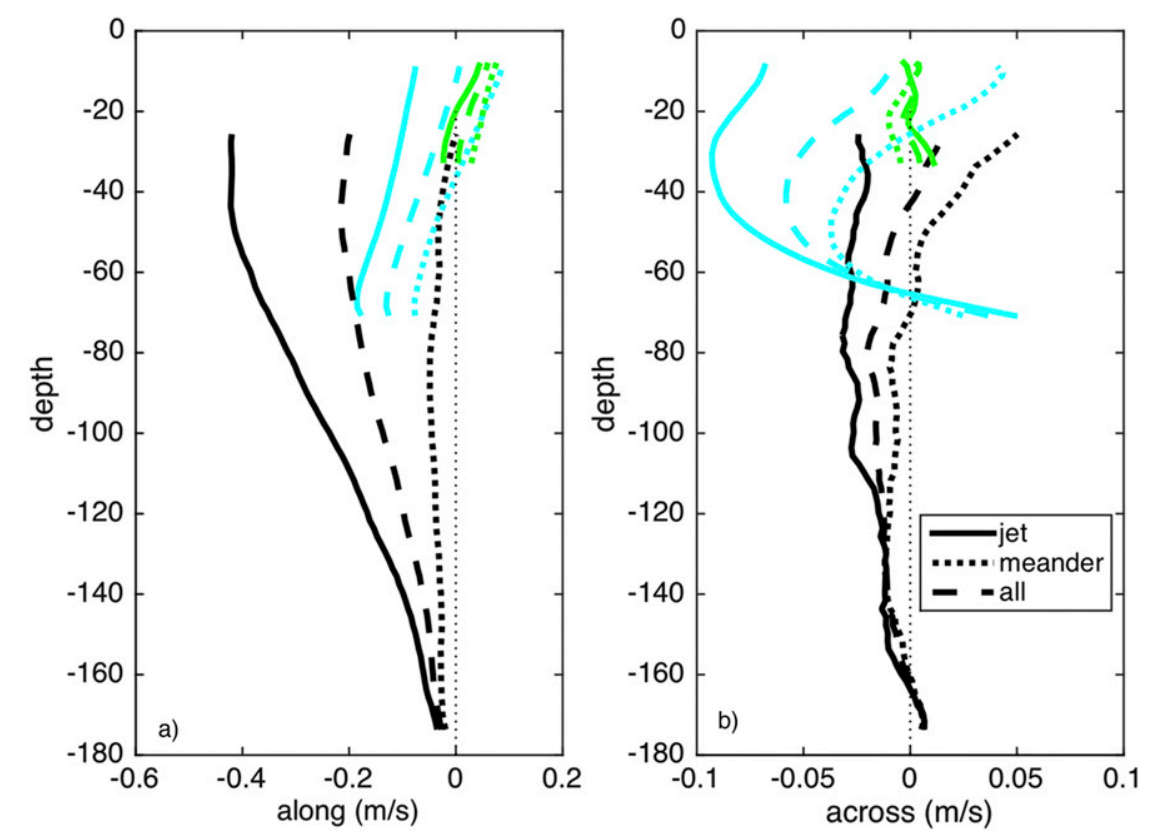

FIG. 13. Deployment-long mean profiles of horizontal velocities (dashed); (a) along-shelf and (b) cross-shelf and conditional means during jets (solid, 20 Jan-24 Feb 2012) and during meanders (dotted, 23 Feb-3 Apr 2012) from the three mooring locations (midshelf, green; shelf break, cyan; upper slope, black).

In addition, the surface signature of an USJ in thermal imagery progresses equatorward as it elongates, rather than progressing poleward, as is typical of filaments. Further, the equatorward flow within the USJ is sustained and does not reverse, and leads to net transport, unlike meander-driven currents. Taken together, these differences indicate the USJs are distinct from warm filaments and likely driven by different dynamics.

The USJ appears to be in approximate thermal wind balance below an approximately $60 \mathrm{~m}$ deep surface mixed layer (Fig. 11). The strong vertical shear in the mixed layer on the offshore side of the jet corresponds with a strong cross-shelf density gradient, but elsewhere in the surface layer the observed shear is often weaker or of opposite sign than the density gradients. Winds of $8-10 \mathrm{~m} \mathrm{~s}^{-1}$ to the northeast, opposing the USJ, were present as the shipboard surveys shown in Fig. 5 began, and explain the positive shears observed. These winds weakened and reserved direction by the end of the survey. Vertical shears on the shoreward side of the USJ, where water depth decreases to $50 \mathrm{~m}$ and less, are less than predicted by the cross-shelf density gradients. Examination of the thermal wind balance on the New Jersey shelf by Yankovsky (2006) also found observed shears to be weaker than geostrophic shears and they suggest turbulent mixing to explain the difference.

We speculate that the USJs exist, or are most likely to exist, when the Gulf Stream is in a strongly deflected mode. A practical issue is sufficient room between the shelf break and the Gulf Stream for the USJ to occupy without being sheared apart or advected poleward by the presence of the much larger Gulf Stream. Proximity of a boundary current to the coast has been suggested to arrest coastally trapped waves (CTW), for example, the absence of CTW propagation when the Agulhas was too close to the coast (Schumann and Brink 1990). The deflection state of the Gulf Stream during the observation period can be estimated using the criterion outlined in Bane and Dewar (1988): strong deflection is defined by the Stream's shoreward SST front being offshore of the $600-\mathrm{m}$ isobath for at least $50 \mathrm{~km}$ downstream of the Charleston Bump. Application of the Bane and Dewar criterion to available satellite imagery suggests strong deflection during most of February 2012, with more frequent transitions in January and March (Fig. 14), consistent with the notion that USJs are most likely to form when the Gulf Stream is farther offshore.

At least for this observation period, it appears that the jets form the shoreward, equatorward-flowing limb of the Charleston Gyre. The existence of the gyre may be related to the deflection state of the Gulf Stream (Bane et al. 2001), and it may exist only when the Gulf Stream is strongly deflected. If these USJs can exist only during a strongly deflected state, then a more mechanistic explanation of the gyre may be that the closed circulation is completed by the presence of the USJs. 


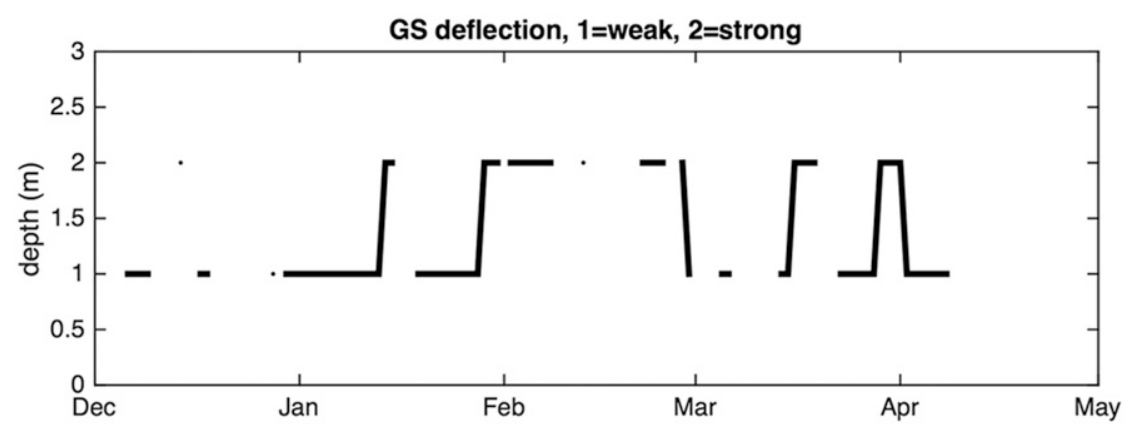

FIG. 14. Gulf Stream deflection state estimated from available AVHRR imagery.

The recirculation associated with the gyre has been linked to enhanced retention and fisheries recruitment (Sedberry et al. 2001; Govoni and Hare 2001) and as such is an important component of the regional circulation.

It may be that the USJs serve at least in part as a response to the shift of the Gulf Stream to a more offshore position. The transition from weakly to strongly deflected modes is associated on average with a $30 \mathrm{~km}$ offshore shift (Zeng and He 2016). Assuming the shift is greatest near the Bump, a decrease to zero shift over an alongshore scale of $200 \mathrm{~km}$ (taken from Fig. 1) gives an average translation over this distance of $15 \mathrm{~km}$. The depth in this location is $400 \mathrm{~m}$, thus a volume of roughly $1.2 \times 10^{12} \mathrm{~m}^{3}$ is required to flow into the space shoreward of the Gulf Stream as it shifts offshore to a strongly deflected state. Bane and Dewar (1988) find that the transition between states can happen rapidly, "a few days at a given site," thus conservatively assuming the shift occurs over a week, this translates into a 2-Sv inflow rate. Cool, dense offshore waters clearly flow into the gyre from deep within or below the Stream to create the cold dome of the Charleston Gyre, but it may be that the USJ satisfies some of this volume requirement. Once the USJ is established and forms the return branch of the Gyre, the USJ is simply an onshore recirculation feature of the Gulf Stream.

The initiation of the USJs was not observed, but given its resemblance to the jetlike intrusions observed by Zhang and Gawarkiewicz (2015), and the apparent connection between the elongated warm features in Fig. 2 and meander crests of the Gulf Stream, we propose that Gulf Stream interactions with the coastal boundary give rise to the USJs. The PNIs described by Zhang and Gawarkiewicz (2015) arise through interaction of a warm-core ring with the continental margin; vortex squashing of fluid with initial anticyclonic relative vorticity leads to self-sustaining equatorward flow. As mentioned above, Shi and Nof (1994) demonstrated that eddy interactions with a boundary can give rise to shore-parallel jets. However, equatorward jets were only found to occur when anticyclonic eddies interacted with the boundary.

Crests of the meanders along the inshore side of the Gulf Stream have a sense of curvature that produces anticyclonic vorticity. The across-stream shear inshore of the jet axis produces cyclonic vorticity. If the curvature vorticity exceeds the across-stream shear vorticity, then the total relative vorticity would be anticyclonic and consistent with the PNI initiation mechanism. Assuming flow along streamlines in polar coordinates, this condition will be met when $V_{t} / R>\partial V_{t} / \partial r$, where $V_{t}$ is the tangential velocity, $R$ is the radius of curvature, and $r$ is the radial direction. Assuming a maximum speed of $2 \mathrm{~m} \mathrm{~s}^{-1}$ and a width of the cyclonic shear zone of $50 \mathrm{~km}$ (cf. Todd et al. 2016) gives an estimate of the shear term $\partial V_{t} / \partial r=4 \times 10^{-5} \mathrm{~s}^{-1}$. For curvature vorticity $V_{t} / R$ to exceed this value requires that $R<$ $12.5-37.5 \mathrm{~km}$ for $V_{t}=0.5-1.5 \mathrm{~m} \mathrm{~s}^{-1}$. Reduced crossstream shear near the axis of the jet would lead a larger maximum value of $\mathrm{R}$ to satisfy the inequality; for example, at half the cross-stream shear estimate above, $R<75 \mathrm{~km}$ for $V_{t}=1.5 \mathrm{~m} \mathrm{~s}^{-1}$.

We are unaware of published estimates of these terms along this section of the Gulf Stream. Bower (1989) found meanders downstream of Cape Hatteras to have curvature radii of roughly $100 \mathrm{~km}$ using RAFOS float trajectories. Using underwater glider measurements downstream of Cape Hatteras, Todd et al. (2016) present a statistical distribution of inverse radius of curvature for which $R>100 \mathrm{~km}$ for the majority of the observations but with distribution tails representing some small fraction with $R<50 \mathrm{~km}$. More recent glider observations within the Gulf Stream along the SAB (J. Heiderich 2018, personal communication) indicate nearly identical curvature distributions along the SAB and downstream of Cape Hatteras. In about $5 \%$ of these observations, curvature vorticity exceeds cross-stream shear, thus producing negative relative vorticity. 
It therefore seems plausible that meanders of large enough amplitude could result in regions of anticyclonic relative vorticity inshore of the axis of the Gulf Stream and mimic the PNI initiation process. The USJs observed in the 2012 field work appear to have initiated at a point farther downstream (poleward of Long Bay), but the location at which they may initiate is not clear from available data. As noted above, there is also some suggestion that USJ formation is favored when the Gulf Stream is strongly deflected, which also corresponds to larger meanders. Bane and Dewar (1988) note "very strong anticyclonic flow" around meander crests when the Gulf Stream is strongly deflected at the Charleston Bump. It seems likely that initiation of an USJ is a somewhat uncommon event, requiring that a threshold amplitude of a meander crest be exceeded, which produces curvature vorticity greater than that due to cross-stream shear, and at a location where interaction with slope topography produces sufficient squashing for USJ formation, but clearly, this topic deserves further investigation.

\section{Conclusions}

Observations collected during winter 2012 inshore of the Gulf Stream where it deflects seaward at the Charleston Bump find equatorward-flowing upper-slope jets, centered on the $200-\mathrm{m}$ isobath and of $30-\mathrm{km}$ width, to dominate the upper-slope density and velocity field for several weeks. Density field adjustment is greatest at depth, where warm waters flood the bottom, raising temperatures by $7^{\circ} \mathrm{C}$. Maximum transport, estimated from repeated shipboard ADCP crossings, is $2.0 \mathrm{~Sv}$. The strongest event lasted approximately 21 days; other events last several days to more than a week.

The USJs occurred when the Gulf Stream was in a strongly deflected state at the Charleston Bump. We speculate that the USJs cannot exist when the Gulf Stream is weakly deflected because there is not sufficient room between the shelf break and Gulf Stream without excessive lateral shear. The strong equatorward flow in the USJs dominates the deployment-long mean along-shelf velocity profile and at least during the sampling period, the USJs form the equatorward limb of the Charleston Gyre. It may be that the USJs help satisfy some fraction of the volume requirement over the upper slope created when the Gulf Stream shifts from a weakly deflected to strongly deflected state.

The USJs bear a strong resemblance to Pinocchio's Nose Intrusions (PNI) described by Zhang and Gawarkiewicz (2015). The dynamics of the PNI suggest fluid with negative relative vorticity (anticyclonic) will form an equatorward-flowing along-shelf jet as it interacts with bathymetry, and we propose that this condition is met when the vorticity contribution from the anticyclonic curvature of a Gulf Stream meander crest is sufficiently strong to overcome the cyclonic shear vorticity along the shoreward side of the Gulf Stream. Possible approaches to confirming this proposal include careful examination of existing high-resolution models of this region, for example, Gula et al. $(2015,2016)$ or ship-based observations guided by SST imagery.

Acknowledgments. This project was supported by National Science Foundation Grants OCE-1032285 (SkIO) and OCE-1032276 (UNC-CH). Data used in this manuscript are available at bco-dmo.org under the project titled: Project: Mechanisms of nutrient input at the shelf margin supporting persistent winter phytoplankton blooms downstream of the Charleston Bump. In addition to the authors, the project team included: Jim Nelson, Trent Moore, Charles Robertson, and Julie Amft (SkIO); Sara Haines, Chris Calloway, Steve Lockhart, and William Stark (UNC-CH); Dongsik Chang, Klementyna Szwaykowska, and Fumin Zhang (Georgia Institute of Technology). We thank the captain and crew of the R/V Savannah for their outstanding support of the field program. We thank John Bane for his very helpful insights and comments on the manuscript, Joleen Heiderich for her analysis of Gulf Stream glider observations, and the anonymous reviewers for their comments.

\section{REFERENCES}

Bane, J., and W. Dewar, 1988: Gulf Stream bimodality and variability downstream of the Charleston Bump. J. Geophys. Res., 93, 6695-6710, https://doi.org/10.1029/JC093iC06p06695.

, D. Brooks, and K. Lorenson, 1981: Synoptic observations of the three-dimensional structure and propagation of Gulf Stream meanders along the Carolina continental margin. J. Geophys. Res., 86, 6411-6425, https://doi.org/10.1029/JC086iC07p06411.

— L. L. P. Atkinson, and D. A. Brooks, 2001: Gulf stream physical oceanography at the Charleston Bump: Deflection, bimodality, meanders and upwelling. Island in the Stream: Oceanography and Fisheries of the Charleston Bump, edited by G. R. Sedberry, American Fisheries Society, 25-36.

Blanton, B., and Coauthors, 2004: Barotropic tides in the South Atlantic Bight. J. Geophys. Res., 109, C12024, https://doi.org/ 10.1029/2004JC002455.

Bower, A., 1989: Potential vorticity balances and horizontal divergence along particle trajectories in Gulf Stream meanders east of Cape Hatteras. J. Phys. Oceanogr., 19, 1669-1681, https://doi.org/10.1175/1520-0485(1989)019<1669:PVBAHD> 2.0.CO;2.

Garau, B., S. Ruiz, W. Zhang, A. Pascual, E. Heslop, J. Kerfoot, and J. Tintore, 2011: Thermal lag correction on Slocum CTD glider data. J. Ocean. Atmos. Tech, 28, 1065-1071, https:// doi.org/10.1175/JTECH-D-10-05030.1.

Gawarkiewicz, G., and D. Chapman, 1992: The role of stratification in the formation and maintenance of shelf-break fronts. 
J. Phys. Oceanogr., 22, 753-772, https://doi.org/10.1175/ 1520-0485(1992)022<0753:TROSIT >2.0.CO;2.

, J. H. Churchill, F. Bahr, C. A. Linder, and C. Marquette, 2008: Shelfbreak frontal structure and processes north of Cape Hatteras in winter. J. Mar. Res., 66, 775-799, https://doi.org/ 10.1357/002224008788064595.

Glenn, S., and C. Ebbesmeyer, 1994a: The structure and propagation of a Gulf Stream frontal eddy along the North Carolina shelf break. J. Geophys. Res., 99, 5029-5046, https://doi.org/ 10.1029/93JC02786.

- and — 1994b: Observations of Gulf Stream frontal eddies in the vicinity of Cape Hatteras. J. Geophys. Res., 99, 50475055, https://doi.org/10.1029/93JC02787.

Govoni, J. J., and J. A. Hare, 2001: The Charleston Gyre as a spawning and larval nursery habitat for fishes. Island in the Stream: Oceanography and Fisheries of the Charleston Bump, edited by G. R. Sedberry, American Fisheries Society, 123-136.

Gula, J., J. Molemaker and J. McWilliams, 2015: Gulf Stream dynamics along the southeastern U.S. seaboard. J. Phys. Oceanogr., 45, 690-715, https://doi.org/10.1175/JPO-D-14-0154.1.

$\longrightarrow,-$, and 2016: Submesoscale dynamics of a Gulf Stream frontal eddy in the South Atlantic Bight. J. Phys. Oceanogr., 46, 305-325, https://doi.org/10.1175/JPO-D-14-0258.1.

Lee, T., J. Yoder, and L. Atkinson, 1991: Gulf Stream frontal eddy influence on the productivity of the southeast U.S. continental shelf. J. Geophys. Res., 96, 22 191-22 205, https://doi.org/ 10.1029/91JC02450.

Legeckis, R., 1979: Satellite observations of the influence of bottom topography on the seaward deflection of the Gulf Stream off Charleston, South Carolina. J. Phys. Oceanogr., 9, 483-497, https://doi.org/10.1175/1520-0485(1979)009<0483:SOOTIO> 2.0.CO;2.

Miller, J., 1994: Fluctuations in Gulf Stream frontal position between Cape Hatteras and the Straits of Florida. J. Geophys. Res., 99, 5057-5064, https://doi.org/10.1029/93JC03484.

Nikolopoulos, A., R. S. Pickart, P. S. Fratantoni, K. Shimada, D. J. Torres, and E. P. Jones, 2009: The western Arctic boundary current at $152^{\circ} \mathrm{W}$ : Structure, variability, and transport. Deep-Sea Res. II, 56, 1164-1181, https://doi.org/10.1016/j.dsr2.2008.10.014.

Pingree, R., G. Mardell, P. Holligan, D. Griffiths, and J. Smithers, 1982: Celtic Sea and Armorican current structure and vertical distributions of temperature and chlorophyll. Cont. Shelf Res., 1, 99-116, https://doi.org/10.1016/0278-4343(82)90033-4.

Schmitz, W. J., Jr., J. R. Luyten, and R. Schmitt, 1993: On the Florida Current T/S Envelope. Bull. Mar. Sci., 53, 1048-1065.

Schumann, E., and K. Brink, 1990: Coastal-trapped waves off the coast of South Africa: generation, propagation and current structures. J. Phys. Oceanogr., 20, 1206-1218, https://doi.org/ 10.1175/1520-0485(1990)020<1206:CTWOTC >2.0.CO;2.

Sedberry, G. R., J. C. McGovern, and O. Pashuk, 2001: The Charleston Bump: An island of essential fish habitat in the Gulf Stream. Island in the Stream: Oceanography and Fisheries of the Charleston Bump, edited by G. R. Sedberry, American Fisheries Society, 3-24.

Shi, C., and D. Nof, 1994: The destruction of lenses and generation of wodons. J. Phys. Oceanogr., 24, 1120-1136, https://doi.org/ 10.1175/1520-0485(1994)024<1120:TDOLAG>2.0.CO;2.

Todd, R. E., W. B. Owens, and D. L. Rudnick, 2016: Potential vorticity structure in the North Atlantic western boundary current from underwater glider observations. J. Phys. Oceanogr., 46, 327-348, https://doi.org/10.1175/JPO-D-15-0112.1.

von Appen, W.-J., and R. S. Pickart, 2012: Two configurations of the Western Arctic Shelfbreak Current in summer. J. Phys. Oceanogr., 42, 329-351, https://doi.org/10.1175/JPO-D-11-026.1.

Yankovsky, A., 2006: On the validity of the thermal wind balance in alongshelf currents off the New Jersey coast. Cont. Shelf Res., 26, 1171-1183, https://doi.org/10.1016/j.csr.2006.03.008.

Zeng, X., and R. He, 2016: Gulf Stream variability and a triggering mechanism of its meander in the South Atlantic Bight. J. Geophys. Res. Oceans, 121, 8021-8038, https://doi.org/10.1002/2016JC012077.

Zhang, W. G., and G. G. Gawarkiewicz, 2015: Dynamics of the direct intrusion of Gulf Stream ring water onto the MidAtlantic Bight shelf. Geophys. Res. Lett., 42, 7687-7695, https://doi.org/10.1002/2015GL065530. 